
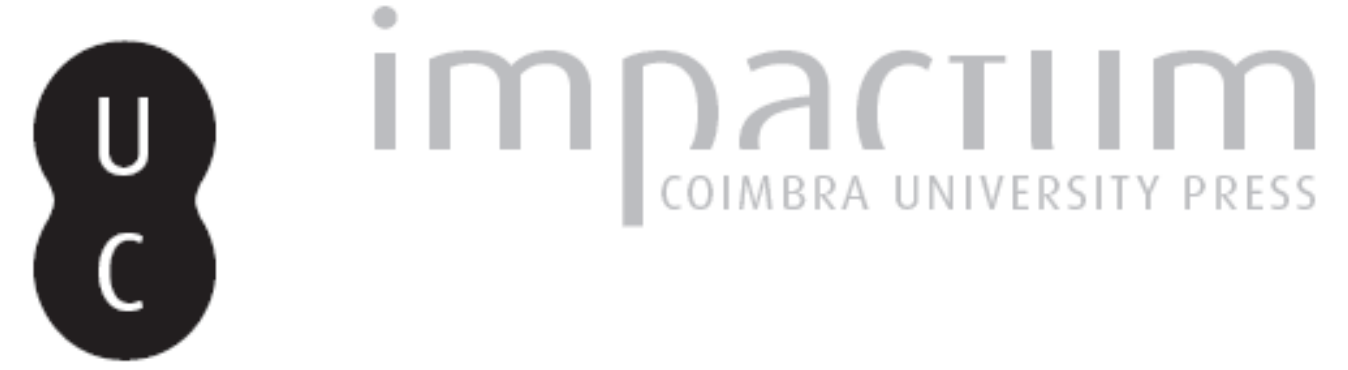

\title{
[Recensão a] Ulrich Horst, Die Diskussion um die Immaculata Conceptio im Dominakanerorden. Ein Beitrag zur Geschichte der theologischen Methode.
}

Autor(es): $\quad$ Rodrigues, Manuel Augusto

Publicado por: Imprensa da Universidade de Coimbra

URL persistente:

URI:http://hdl.handle.net/10316.2/45345

DOI:

DOI:https://doi.org/10.14195/2183-8925_9-3_19

Accessed : $\quad$ 26-Apr-2023 15:44:57

A navegação consulta e descarregamento dos títulos inseridos nas Bibliotecas Digitais UC Digitalis, UC Pombalina e UC Impactum, pressupõem a aceitação plena e sem reservas dos Termos e Condições de Uso destas Bibliotecas Digitais, disponíveis em https://digitalis.uc.pt/pt-pt/termos.

Conforme exposto nos referidos Termos e Condições de Uso, o descarregamento de títulos de acesso restrito requer uma licença válida de autorização devendo o utilizador aceder ao(s) documento(s) a partir de um endereço de IP da instituição detentora da supramencionada licença.

Ao utilizador é apenas permitido o descarregamento para uso pessoal, pelo que o emprego do(s) título(s) descarregado(s) para outro fim, designadamente comercial, carece de autorização do respetivo autor ou editor da obra.

Na medida em que todas as obras da UC Digitalis se encontram protegidas pelo Código do Direito de Autor e Direitos Conexos e demais legislação aplicável, toda a cópia, parcial ou total, deste documento, nos casos em que é legalmente admitida, deverá conter ou fazer-se acompanhar por este aviso.

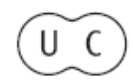




\section{REVISTA DE HISTÓRIA DAS IDEIAS 9}

\section{O SAGRADO E O PROFANO ***}

HOMENAGEM A J. S. DA SILVA DIAS

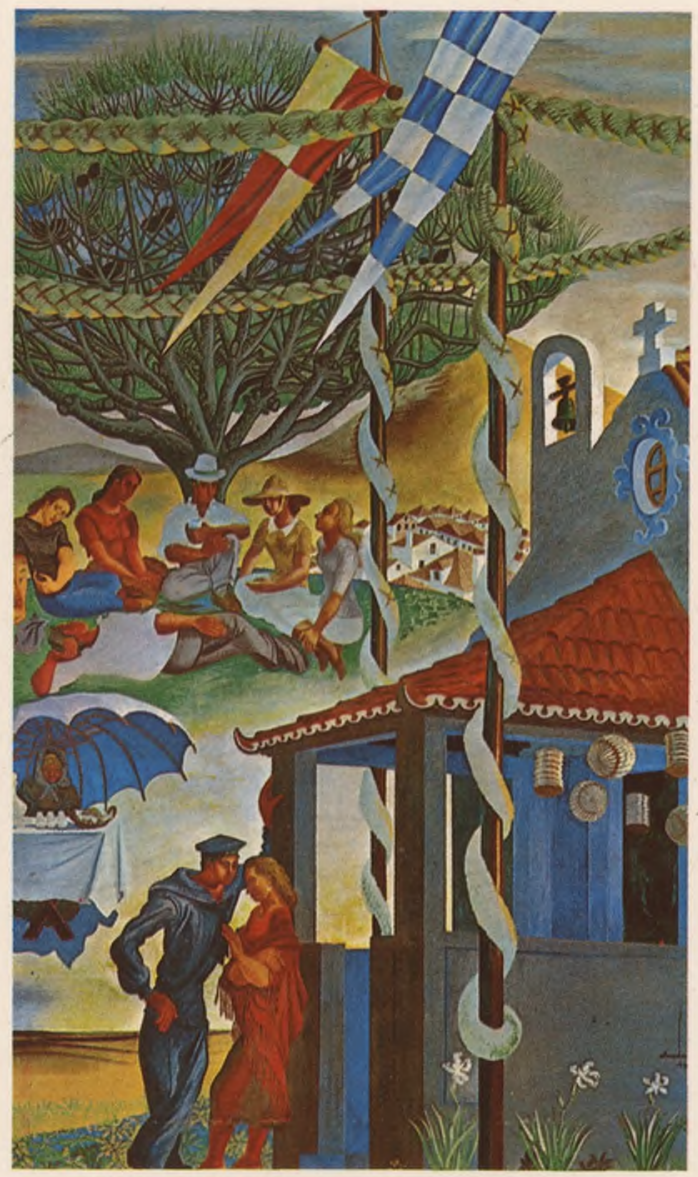

INSTITUTO DE HISTÓRIA E TEORIA DAS IDEIAS FACULDADE DE LETRAS 
que possa analisar com a profundidade desejada os pontos escolhidos pelo autor, perante uma imensidade de questões que poderiam ser abordadas? Obviamente que não. Por isso desejo salientar que os problemas equacionados, mais do que críticas à obra de Amado Mendes, devem ser entendidos como interrogações que lhe são endereçadas e que ocupam igualmente e de forma constante a nossa consciência crítica.

$O$ certo é que, apesar de algumas reticências que naturalmente podem surgir quando se analisa o «manual» de Amado Mendes - quer quanto à sua estrutura pedagógico-didáctica e científica, quer quanto a algumas análises pontuais - se trata de uma obra do maior interesse para os estudantes e para todos aqueles que desejam iniciar-se nos métodos e nos problemas que a História implica. $O$ que é importante, todavia, é que o livro leve cada leitor a uma análise crítica do seu conteúdo e a questionamentos fundamentais. É esse, de resto - não tenho dúvida em o afirmar o desejo do autor. Por isso estou certo que esta reflexão apenas servirá para enriquecer o nosso diálogo sobre o que é a História - ela será, na verdade, uma Ciência? E, se sim, que Ciência?

\section{Luís Reis Tor gal}

Ulrich Horst, Die Diskussion um die Immaculata Conceptio im Dominakanerorden. Ein Beitrag zur Geschichte der theologischen Methode. Veröffentlichungen des Grabmann-Institutes zur Erforschung der mittelalterlichen Theologie und Philosophie herausgegeben von Michael Schmaus, Werner Dettloff, Richard Heinzmann, Ulrich Horst. Neue Folge n. ${ }^{\circ}$ 34. Ferdinand Schöningh, Paderborn - München - Wien - Zürich, 1987 XIX + 123 p.

Como diz o autor na introdução, são hoje cada vez mais raros os estudos sobre a historia da Mariologia. Para muitos teólogos dominicanos notáveis é a Imaculada Conceição um sinal de contradição. Segundo eles, tratava-se não duma disputa, como as que sucediam entre ordens e escolas rivais, mas de questões fundamentais acerca do método teológico exacto, e do papel e peso das autoridades clássicas. Isto explica a oposição apaixonada contra a opinião nova, a qual a conduzia finalmente a um isolamento com consequências trágicas. Ulrich Horst depois de referir as fontes (manuscritas e impressas) e a mais actualizada bibliografia apresenta uma 


\section{Revista de Historia das Ideias}

introdução concebida de forma excelente as linhas mestras do desenvolvimento da discussão teológica acerca da Imaculada Conceição. $\mathrm{O}$ autor fica assim a conhecer em síntese os caminhos seguidos ao longo da história, o que lhe fornece uma preparação ideal para a leitura dos diversos capítulos da obra.

O cap. I trata da discussão medieval; o cap. II da nota de Caetano para o Papa Leão $X$ e da apresentação da posição tomista no séc. XVI; o cap. Ill da fundamentação e evolução da tese masculina de Bartolomeu Spina (f 1547), Bartolomeu Medina, Dominicus Báñez, Pedro de Herrera e Francisco de Araújo e João de S. Tomás; o cap. IV dos adeptos da «nova opinião» da ordem dominicana: Francisco Vitoria, Juan de la Peña, Tomás Malvenda, Vicente Iustiniano Antist e Ambrosius Catharinus; finalmente, o cap. $\mathrm{V}$ aborda o tema: $\mathrm{O}$ Cursus Theologicus Salmanticensis e a tradição tomista.

Ao longo do texto, sempre bem fundamentado e acompanhado de citações apropriadas e deveras esclarecedoras, podemos acompanhar o pensamento dos autores mais representativos acerca da Imaculada Conceição.

A alusão frequente a outros autores, além dos acima mencionados, e a diversos acontecimentos da vida da Igreja e da sociedade, constituem dados extremamente importantes para ajudar a compreender a evolução dum poblema que tanto preocupou os teólogos ao longo da história da Igreia, mesmo de outras ordens religiosas, como as da Companhia de Jesus (S. Roberto Belarmino e Suárez, por exemplo) e dos Eremitas de Santo Agostinho (caso do português Fr. Egídio da Apresentação). Aliás, na Universidade de Coimbra o juramento da Imaculada Conceição veio ocupar um papel importante. Sobre o assunto escreveu um notável trabalho o Doutor António de Vasconcelos.

Um apêndice documental com texto de Francisco Vitória (manuscrito existente na Biblioteca da Ajuda), de Juan de la Peña (no Vaticano) e de Dominicus Soto (na Staatsbibliothek de Munique) enriquecem a obra, bem como um índice de autores.

Trata-se de um livro de grande valor que vem preencher uma grande lacuna pois, como se sabe, a doutrina da Imaculada Conceição foi bastante controversa. O autor que conhece como poucos a história da teologia medieval e moderna, em particular a da Península Ibérica, fruto de inúmeras pesquisas e estudos realizados, presta assim um valioso contributo à história da cultura em geral, inclusive da portuguesa. 


\section{Recensões}

A alusão a vários autores portugueses ou que ensinaram no País reveste-se, por isso, de grande significado.

Manuel Augusto Rodrigues

Synodicon Hispanum, vol. IV: Ciudad Rodrigo, Salamanca y Zamora. Edición critica dirigida por Antonio Garcia y Garcia. Bibliotheca de Autores Cristianus. Madrid, 1987. $\mathrm{XX}+474 \mathrm{p}$.

O plano geral da obra do Synodicon Hispanum abrange os seguintes volumes: I - Galicia; II - Portugal; III - Astorga, Leon e Oviedo; IV - Ciudad Rodrigo, Salamanca e Zamora; V - Extremadura, Badajoz, Coria, Cáceres e Plasencia; VI - Castilla; VII - Andalucia e Canarias; VIII - Valencia; IX - Aragon e Navarra; X - Cataluña e Baleares. Já estão publicados os primeiros auatro volumes.

O presente volume foi preparado por Bernardo Alonso Rodriguez, Federico R. Aznar Gil, Francisco Cantelar Rodriguez, Antonio Garcia y Garcia e José Sanchez Herrero; e foi realizado e subvencionado no quadro dos planos de investigação da «Comisión Asesora de Investigación Científica y Técnica» do Ministério da Educação e Ciência, dentro do programa «Fuentes del Derecho do Instituto de Ciencias Juridicas» do Consejo Superior de Investigaciones Científicas, e com o apoio da Caja de Ahorros de Piedad de Salamanca.

São ao todo 14 os sínodos das três dioceses referidas no título, sendo 1 de Ciudad Rodrigo (séc. XV), 10 de Zamora (6 do séc. XIV e 4 do séc. XV); e 13 de Salamanca (1 do séc XIII, 6 do séc. XIV e 6 do séc. XV). Entre os volumes já editados, este é o que tem menos número de sínodos. Mas tem a vantagem sobre os demais pelo facto de incluir o Liber Synod alis de D. Gonzalo Alba, de 6 de Abril de 1410, e a sua versão intitulada Libro sinodal. Trata-se de um texto de grande importância. Salamanca é, como se vê, a diocese com a maioria de textos. Excepto em Zamora, a actividade sinodal começa tarde e acaba a partir de 1500 para se reiniciar depois do Concílio de Trento.

Antes da apresentação dos textos sinodais de cada diocese, encontramos uma introdução que se reveste de enorme interesse para a compreensão dos mesmos e suas fontes e da vida dos prelados. 